\title{
Epigenetic control of retrotransposons in adult tissues: Implications for immune regulation
}

\author{
Running title: Epigenetic control of retrotransposons in adult tissues \\ Christopher H.C. Tie and Helen M. Rowe* \\ Division of Infection and Immunity, University College London, 90 Gower Street, \\ London WC1E 6BT, UK \\ *Correspondence: h.rowe@ucl.ac.uk
}

\begin{abstract}
Retrotransposons tune immune reactivity in differentiated cells because when they are transcribed, their nucleic acids can be viewed as non-self leading to innate immune sensing. Most retrotransposons, however, are subject to transcriptional regulation by a multitude of epigenetic pathways, which have coevolved with them for millions of years. While a lot is known about the epigenetic control of retrotransposons in germ cells and early embryos, surprisingly little is understood about these pathways in adult tissues, particularly in human cells. Recent evidence suggests that retrotransposon repression persists in differentiated cells and is dynamic. Future insight into this topic may teach us how to reactivate or silence specific retrotransposon families, to promote anti-tumour immunity or dampen autoimmunity through epigenetic modulation.
\end{abstract}

\section{Introduction}

Transposable elements (TEs) are mobile genetic elements aptly named "controlling elements" by Barbara McClintock in the 1950s because of their ability to control cellular genes [1]. Since their discovery, the advancement of genome sequencing and bioinformatics technologies has led to the identification of a huge number of TE families, the functions of which are now being unraveled. Retrotransposons are particularly relevant TEs because they can replicate through an RNA intermediate, allowing them to insert new DNA copies of themselves into the genome. This has enabled them to accumulate over millions of years and they now comprise more than half of the human genome[2]. Over 
time, deleterious insertions are negatively selected while those beneficial to the host become co-opted and fixed in the genome[3]. Co-opted retrotransposons are often from the endogenous retrovirus (ERV) class, which dates back hundreds of millions of years [4]. Although retrotransposons are overall beneficial as a driving force behind the evolution of new genes and non-coding DNA[5, 6], they can also compromise genome and transcriptome integrity [7]. A multitude of epigenetic pathways, therefore, act in early development to constrain their transcription and some of these strategies remain active in differentiated cells.

Epigenetics refers to modifications on chromatin, rather than DNA sequence alterations, which lead to heritable effects on gene expression. Chromatin is subject to histone modifications and cytosine methylation and distinct epigenetic marks are associated with an active and silent gene expression state. For example, acetylation of histone 3 at the lysine residue at position 27 (H3K27ac) is a chromatin signature associated with active genes and enhancers[8], whereas trimethylation of histone 3 at the lysine at position 9 (H3K9me3) correlates with heterochromatin and gene silencing[9-11]. Retrotransposons direct both genetic and epigenetic heritable traits because they can integrate into our genome in the germ line and orchestrate epigenetic alterations through the recruitment of transcription factors to their regulatory elements [12].

Since half of the human genome is derived from retrotransposons, it can be viewed as non-self. Although most human retrotransposons are no longer mobile, expression of their nucleic acids and proteins can lead to the formation of pathogen-associated molecular patterns (PAMPs) and antigens that we refer to here as "neo-antigens" that could potentially elicit an immunological response. Retrotransposons, are therefore situated at the interface of immune reactivity; when enriched in silent chromatin they are transcriptionally inactive and immune masked, whereas when expressed they may trigger innate and adaptive immunity [13-15]. In this review, we will discuss the mechanisms in place to maintain retrotransposons silent in differentiated cells and the implications of these pathways. We will focus here on chromatin readers, writers and erasers 
and the KAP1 and KRAB-ZNF system. The role of small RNAs, while important, is beyond the scope of this review and we direct the reader to a recent review covering this topic[16].

\section{Epigenetic pathways constraining retrotransposons}

Epigenetic silencing of retrotransposons takes place in early embryos and in differentiated tissues, epigenetic states link back to patterns established during development[17]. The identification of factors that maintain repression in postembryonic tissues and how dynamic chromatin marks are in differentiated cell types is a fascinating and emerging area of research. Moreover, existing work relies largely on mouse models so it will be crucial to establish parallels in human cells, where the precise retrotransposons, their activity and their coevolution patterns with genes are distinct[18].

\section{Chromatin readers, writers and erasers}

Chromatin-associated proteins induce epigenetic changes to either histones or DNA and mediate downstream biological functions. Promoter cytosine methylation occurs at ERVs and is associated with gene repression $[19,20]$, whereas intragenic methylation prevents spurious transcription initiation [21]. Interestingly, human ERV-K (HERV-K) genomic sequences have undergone selection to mutate $\mathrm{CpG}$ dinucleotides, presumably to escape repression through DNA methylation [22]. De novo methylation is carried out by DNMT3A, DNMT3B, the newly discovered rodent-specific DNMT3C, and the cofactor DNMT3L [2326] and maintained by DNMT1 through cell divisions [27, 28]. Defective DNMT1 leads to DNA hypomethylation and ERV overexpression and plays a causative role in the onset of cancer and autoimmune disease $[29,30]$. Interestingly, the reactivation of ERVs observed following treatment of cells with DNAdemethylating agents, such as 5-azacytidine (5-AZA) [31] has been proposed to be responsible for driving anti-tumour immunity in cancer patients treated with these drugs through innate sensing of ERV nucleic acids $[13,14]$. 5-AZA drugs are thought to target mainly DNMT3A and DNMT3B, which can be increased in expression upon differentiation [32], in contrast to DNMT3L, which is not expressed in differentiated cells [33]. 
Histone methyltransferases (HMTs) including SETDB1 (also known as ESET), SUV39h and G9a (also known as EHMT2) mediate retrotransposon repression through histone methylation $[9,10,34]$. The most relevant to this review is SETDB1 because it is required for retrotransposon repression in postembryonic tissues $[35,36]$. Indeed, the finding that SETDB1 represses ERVs in committed mouse B-lineage cells, has led to a new paradigm that SETDB1 and potentially other histone modifiers remain important in differentiated cells [35]. Interestingly, loss of silent chromatin at SETDB1-regulated ERVs is not sufficient for their activation and the precise panel of ERVs reactivated in specific cell types depends on the transcription factors available [35]. HP1 too, which interacts with H3K9me3 [37, 38] and participates in heterochromatin spreading [39] has been implicated in silencing of ERVs including in differentiated cells [40,41].

\section{The KAP1 and KRAB-ZNF repertoire}

The KAP1 and KRAB-ZNF (KRAB-zinc finger protein) system silences retrotransposons in early embryos and embryonic stem cells (ESCs) [12, 42, 43]. It has likely evolved in response to retrotransposon invasions [44] because KRAB-ZNF transcription factors are largely specific for transposon sequences [45-47] but now this pathway also participates in gene regulation $[45,48,49]$. KAP1 is recruited to transposons through the interaction of its RING, B-box and coiled-coil (RBCC) domain with the KRAB domain of KRAB-ZNFs. Transcriptional repression is mediated through co-factors such as SETDB1[5052], which prevents binding of transcriptional activators[53, 54]. There are several hundred KRAB-ZNFs [55], which can be viewed as a panel of effector proteins specific for foreign DNA in the same way that an antibody repertoire is specific for foreign antigens. While many KRAB-ZNFs have recently been matched to their target sequences through chromatin immunoprecipitation experiments [45-47], only a few have been functionally characterized. These include human ZNF91 and ZNF93, which recognize specific SVA and LINE1 subfamily sequences, respectively [56]. The KAP1 and KRAB-ZNF pathway is functional in human and mouse ESCs and neural progenitor cells [42, 57-59] but little is known about its role in differentiated cells. However, one study showed 
that KAP1 binds to certain ERV-K elements in human primary CD4+ T cells [59]. It was also reported that KAP1 and KRAB-ZFPs bind to several ERVs in mouse liver. Interestingly, while KAP1 knockout in the liver had little impact on the expression of these ERVs, several co-regulated cellular genes were affected [48]. This suggests that redundant mechanisms may converge to silence ERVs in differentiated cells [48]. Surprisingly, HSP90 has recently been implicated in the formation of a KAP1 repressor complex at ERVs [60]. Like KAP1, HSP90 is necessary to maintain silent chromatin at ERVs and prevent aberrant transcription of genes close to the ERVs that it regulates $[49,60]$. Most interestingly, this is true not only in ESCs but also in differentiated macrophages [60]. The nucleosomal and remodeling deacetylase (NuRD) complex, which interacts with KAP1 has also been implicated in retrotransposon repression in differentiated cells [61].

Of note, not all ERV-derived sequences are subject to epigenetic silencing as some have been co-opted because their non-coding DNA regulatory elements, nucleic acids or even gene products benefit their hosts $[5,6,62,63]$. Whether coopted ERVs are subject to spatial or temporal repression by KAP1 remains an open question. However, certain KRAB-ZNFs have been found to bind to coopted ERVs and to recruit transcriptional activators and pioneer factors, suggesting that these ZNFs function to switch on rather then switch off certain gene networks $[45,47]$.

\section{Implications for immune regulation}

ERVs have been implicated in multiple cancers and autoimmune diseases, including ovarian and breast cancer, systemic lupus erythematosus and multiple sclerosis [64, 65]. There is some convincing evidence that ERVs can play a causative role in cancer when their LTRs escape epigenetic repression [66] and interestingly, this involves mainly primate-specific ERVs [67]. For example, cryptic enhancers and promoters that reside within ERVs can drive expression of oncogenes[66, 68]. 
ERVs regulate the immune system in several ways. For example, double stranded RNA (dsRNA) produced from retrotransposons, following treatment of cancer cells with DNA methyltransferase inhibitors activates interferon through MDA5, MAVS and IRF7 [13, 14]. Cytoplasmic DNA resulting from reverse transcription also serves as an additional PAMP because it is detected by the cytosolic DNA sensor cGAS to activate type I interferon through STING [63, 69-72]. Likewise, Toll-like receptors contribute to ERV nucleic acid sensing [73]. Mutations within genes involved in nucleic acid metabolism including TREX1 are associated with autoimmune diseases [74], although such factors block classes of retrotransposons that are constitutively transcribed rather than those embedded within silent chromatin. In addition to innate immunity, ERVs can stimulate adaptive immunity too because their encoded gene products, which are necessary for their mobilization are subject to standard antigen processing and presentation pathways. For example, tumour-associated antigens (TAAs) can be derived from HERV-K envelope protein[75]. Such neo-antigens can evoke adaptive $\mathrm{T}$ cell and antibody responses [76], both of which have been demonstrated to regulate ERVs $[15,75]$.

Overall, ERV regulatory sequences including solo LTRs have been described to contribute to cancer by driving oncogenes, whereas longer ERVs if resurrected (for example through 5-AZA treatment) may promote anti-tumour immunity through their nucleic acids and proteins. Exactly how sensing of ERV nucleic acids leads to anti-tumour immunity is not fully understood but remarkably, it has been shown that if cancer initiating cells are pretreated with 5-AZA drugs before their injection into mice, they form less tumours and this phenotype is dependent on MAVS[14]. Likewise, if B16 melanoma cells are pretreated with 5AZA before their injection into mice that receive anti-CTLA-4, they can stimulate complete tumour clearance[13]. Furthermore, interferon-responsive genes are upregulated in cancer patients treated with 5-AZA[77]. Interferon signaling is important presumably to promote apoptosis of cancer cells and to help to recruit cytotoxic $\mathrm{T}$ cells recognizing neo-antigens and other immune effectors to clear the tumour. It has also been shown that cytosolic RNA and DNA sensing of ERVs is necessary to induce T-independent $\mathrm{B}$ cell responses in mice[63]. This latter 
work illustrates that ERVs have coevolved with their hosts to play a natural role in modulating the immune system. Overall, ERVs lie at the intersection of innate and adaptive immunity, due to their intrinsic immunogenicity.

\section{Concluding remarks}

While it was previously thought that histone marks are primarily required to silence retrotransposons only early in development[10, 50, 78, 79], where DNA methylation is reprogrammed $[80,81]$, recent evidence has led to a new paradigm whereby diverse epigenetic modifiers exert continuous roles in adult tissues. Here we discuss evidence that SETDB1, DNMTs, HP1, HSP90, the NuRD complex and potentially KAP1 and KRAB-ZNFs are some of these factors. Importantly, most of these regulators have only been studied in mouse models so far. A future understanding of the pathways operating in adult human tissues is essential for the development of innovative drugs. Targeted epigenetic modulation might prove a potent tool in the future to reactivate certain retrotransposons so that their nucleic acids and proteins could serve as natural PAMPs to signal danger to their host. Such drugs may be valuable to stimulate immunosurveillance in cancer patients in which immune activation pathways may be subdued or could be used in conjunction with standard vaccines in place of an adjuvant. Caution should be applied, however, to prevent unwanted effects of reactivated ERVs on the genome or transcriptome.

\section{Acknowledgements}

We thank Steen K Ooi, Greg Towers, Pierre V Maillard, Luisa Robbez-Masson and Connor Husovsky for helpful comments. This work was supported through a Sir Henry Dale Fellowship jointly funded by the Wellcome Trust and Royal Society (Grant number 101200/Z/13/Z) awarded to HMR and a UCL Grand Challenges Studentship (number 518099) and UCL Overseas Research Scholarship both awarded to CHCT.

\section{$\underline{\text { References }}$}

1. Mc CB: The origin and behavior of mutable loci in maize. Proc Natl Acad Sci U S A 1950, 36(6):344-355. 
2. de Koning AP, Gu W, Castoe TA, Batzer MA, Pollock DD: Repetitive elements may comprise over two-thirds of the human genome. PLoS Genet 2011, 7(12):e1002384.

3. Henzy JE, Gifford RJ, Kenaley CP, Johnson WE: An Intact Retroviral Gene Conserved in Spiny-Rayed Fishes for over 100 My. Molecular biology and evolution 2016.

4. Aiewsakun P, Katzourakis A: Marine origin of retroviruses in the early Palaeozoic Era. Nature communications 2017, 8:13954.

5. Dupressoir A, Vernochet C, Bawa O, Harper F, Pierron G, Opolon P, Heidmann T: Syncytin-A knockout mice demonstrate the critical role in placentation of a fusogenic, endogenous retrovirus-derived, envelope gene. Proc Natl Acad Sci U S A 2009, 106(29):12127-12132.

6. Wang J, Xie G, Singh M, Ghanbarian AT, Rasko T, Szvetnik A, Cai H, Besser D, Prigione A, Fuchs NV et al: Primate-specific endogenous retrovirusdriven transcription defines naive-like stem cells. Nature 2014, 516(7531):405-409.

7. Shukla R, Upton KR, Munoz-Lopez M, Gerhardt DJ, Fisher ME, Nguyen T, Brennan PM, Baillie JK, Collino A, Ghisletti S et al: Endogenous retrotransposition activates oncogenic pathways in hepatocellular carcinoma. Cell 2013, 153(1):101-111.

8. Rada-Iglesias A, Bajpai R, Swigut T, Brugmann SA, Flynn RA, Wysocka J: A unique chromatin signature uncovers early developmental enhancers in humans. Nature 2011, 470(7333):279-283.

9. Bulut-Karslioglu A, De La Rosa-Velazquez IA, Ramirez F, Barenboim M, Onishi-Seebacher M, Arand J, Galan C, Winter GE, Engist B, Gerle B et al: Suv39h-dependent H3K9me3 marks intact retrotransposons and silences LINE elements in mouse embryonic stem cells. Mol Cell 2014, 55(2):277-290.

10. Matsui T, Leung D, Miyashita H, Maksakova IA, Miyachi H, Kimura H, Tachibana M, Lorincz MC, Shinkai Y: Proviral silencing in embryonic stem cells requires the histone methyltransferase ESET. Nature 2010, 464(7290):927-931.

11. Walter M, Teissandier A, Perez-Palacios R, Bourc'his D: An epigenetic switch ensures transposon repression upon dynamic loss of DNA methylation in embryonic stem cells. Elife 2016, 5.

12. Wolf D, Goff SP: Embryonic stem cells use ZFP809 to silence retroviral DNAs. Nature 2009, 458(7242):1201-1204.

13. Chiappinelli KB, Strissel PL, Desrichard A, Li H, Henke C, Akman B, Hein A, Rote NS, Cope LM, Snyder A et al: Inhibiting DNA Methylation Causes an Interferon Response in Cancer via dsRNA Including Endogenous Retroviruses. Cell 2015, 162(5):974-986.

** This and the below paper are the first reports implicating ERVs in the mechanism of anti-tumour immunity induced by 5-AZA treatment in cancer patients.

14. Roulois D, Loo Yau H, Singhania R, Wang Y, Danesh A, Shen SY, Han H, Liang G, Jones PA, Pugh TJ et al: DNA-Demethylating Agents Target Colorectal Cancer Cells by Inducing Viral Mimicry by Endogenous Transcripts. Cell 2015, 162(5):961-973. 
This and the above paper are the first reports implicating ERVs in the mechanism of anti-tumour immunity induced by 5 -AZA treatment in cancer patients.

15. Young GR, Eksmond U, Salcedo R, Alexopoulou L, Stoye JP, Kassiotis G: Resurrection of endogenous retroviruses in antibody-deficient mice. Nature 2012, 491(7426):774-778.

16. Goodier JL: Restricting retrotransposons: a review. Mobile DNA 2016, 7:16.

17. Wolf G, Yang P, Fuchtbauer AC, Fuchtbauer EM, Silva AM, Park C, Wu W, Nielsen AL, Pedersen FS, Macfarlan TS: The KRAB zinc finger protein ZFP809 is required to initiate epigenetic silencing of endogenous retroviruses. Genes Dev 2015, 29(5):538-554.

* The first report of a KRAB-ZFP knockout mouse revealing that absence of Zfp809 in early embryos leads to the upregulation of its target ERVs in differentiated tissues.

18. Campos-Sanchez R, Cremona MA, Pini A, Chiaromonte F, Makova KD: Integration and Fixation Preferences of Human and Mouse Endogenous Retroviruses Uncovered with Functional Data Analysis. PLoS computational biology 2016, 12(6):e1004956.

19. Howard G, Eiges R, Gaudet F, Jaenisch R, Eden A: Activation and transposition of endogenous retroviral elements in hypomethylation induced tumors in mice. Oncogene 2008, 27(3):404408.

20. Walsh CP, Chaillet JR, Bestor TH: Transcription of IAP endogenous retroviruses is constrained by cytosine methylation. Nat Genet 1998, 20(2):116-117.

21. Neri F, Rapelli S, Krepelova A, Incarnato D, Parlato C, Basile G, Maldotti M, Anselmi F, Oliviero S: Intragenic DNA methylation prevents spurious transcription initiation. Nature 2017, 543(7643):72-77.

22. Zsiros J, Jebbink MF, Lukashov VV, Voute PA, Berkhout B: Biased nucleotide composition of the genome of HERV-K related endogenous retroviruses and its evolutionary implications. $J \mathrm{Mol} E \mathrm{Eol}$ 1999, 48(1):102-111.

23. Barau J, Teissandier A, Zamudio N, Roy S, Nalesso V, Herault Y, Guillou F, Bourc'his D: The DNA methyltransferase DNMT3C protects male germ cells from transposon activity. Science 2016, 354(6314):909-912.

* Identification of a novel DNMT gene that represses transposons

24. Chedin F, Lieber MR, Hsieh CL: The DNA methyltransferase-like protein DNMT3L stimulates de novo methylation by Dnmt3a. Proc Natl Acad Sci U S A 2002, 99(26):16916-16921.

25. Okano M, Bell DW, Haber DA, Li E: DNA methyltransferases Dnmt3a and Dnmt3b are essential for de novo methylation and mammalian development. Cell 1999, 99(3):247-257.

26. Ooi SK, Qiu C, Bernstein E, Li K, Jia D, Yang Z, Erdjument-Bromage H, Tempst $\mathrm{P}$, Lin SP, Allis CD et al: DNMT3L connects unmethylated lysine 
4 of histone H3 to de novo methylation of DNA. Nature 2007, 448(7154):714-717.

27. Hutnick LK, Huang X, Loo TC, Ma Z, Fan G: Repression of retrotransposal elements in mouse embryonic stem cells is primarily mediated by a DNA methylation-independent mechanism. J Biol Chem 2010, 285(27):21082-21091.

28. Liao J, Karnik R, Gu H, Ziller MJ, Clement K, Tsankov AM, Akopian V, Gifford CA, Donaghey J, Galonska C et al: Targeted disruption of DNMT1, DNMT3A and DNMT3B in human embryonic stem cells. Nat Genet 2015, 47(5):469-478.

29. Fali T, Le Dantec C, Thabet Y, Jousse S, Hanrotel C, Youinou P, Brooks WH, Perl A, Renaudineau Y: DNA methylation modulates HRES1/p28 expression in B cells from patients with Lupus. Autoimmunity 2014, 47(4):265-271.

30. Gaudet F, Rideout WM, 3rd, Meissner A, Dausman J, Leonhardt H, Jaenisch $\mathrm{R}$ : Dnmt1 expression in pre- and postimplantation embryogenesis and the maintenance of IAP silencing. Mol Cell Biol 2004, 24(4):16401648.

31. Groudine M, Eisenman R, Weintraub H: Chromatin structure of endogenous retroviral genes and activation by an inhibitor of DNA methylation. Nature 1981, 292(5821):311-317.

32. Oka M, Meacham AM, Hamazaki T, Rodic N, Chang LJ, Terada N: De novo DNA methyltransferases Dnmt3a and Dnmt3b primarily mediate the cytotoxic effect of 5-aza-2'-deoxycytidine. Oncogene 2005, 24(19):3091-3099.

33. Kao TH, Liao HF, Wolf D, Tai KY, Chuang CY, Lee HS, Kuo HC, Hata K, Zhang $X$, Cheng $X$ et al: Ectopic DNMT3L triggers assembly of a repressive complex for retroviral silencing in somatic cells. $J$ Virol 2014, 88(18):10680-10695.

34. Leung DC, Dong KB, Maksakova IA, Goyal P, Appanah R, Lee S, Tachibana M, Shinkai Y, Lehnertz B, Mager DL et al: Lysine methyltransferase G9a is required for de novo DNA methylation and the establishment, but not the maintenance, of proviral silencing. Proc Natl Acad Sci U S A 2011, 108(14):5718-5723.

35. Collins PL, Kyle KE, Egawa T, Shinkai Y, Oltz EM: The histone methyltransferase SETDB1 represses endogenous and exogenous retroviruses in B lymphocytes. Proc Natl Acad Sci U S A 2015, 112(27):8367-8372.

** This paper introduces a new paradigm that histone methyltransferases and potentially other epigenetic modifiers are required for retrotransposon repression in differentiated cells

36. Pasquarella A, Ebert A, Pereira de Almeida G, Hinterberger M, Kazerani M, Nuber A, Ellwart J, Klein L, Busslinger M, Schotta G: Retrotransposon derepression leads to activation of the unfolded protein response and apoptosis in pro-B cells. Development 2016, 143(10):1788-1799.

37. Hiragami-Hamada K, Soeroes S, Nikolov M, Wilkins B, Kreuz S, Chen C, De La Rosa-Velazquez IA, Zenn HM, Kost N, Pohl W et al: Dynamic and flexible H3K9me3 bridging via HP1beta dimerization establishes a 
plastic state of condensed chromatin. Nature communications 2016, 7:11310.

38. Lachner M, O'Carroll D, Rea S, Mechtler K, Jenuwein T: Methylation of histone $\mathrm{H} 3$ lysine 9 creates a binding site for HP1 proteins. Nature 2001, 410(6824):116-120.

39. Canzio D, Liao M, Naber N, Pate E, Larson A, Wu S, Marina DB, Garcia JF, Madhani HD, Cooke R et al: A conformational switch in HP1 releases auto-inhibition to drive heterochromatin assembly. Nature 2013, 496(7445):377-381.

40. Sharma P, Azebi S, England P, Christensen T, Moller-Larsen A, Petersen T, Batsche E, Muchardt C: Citrullination of histone $\mathrm{H3}$ interferes with HP1-mediated transcriptional repression. PLoS Genet 2012, 8(9):e1002934.

41. Wolf D, Cammas F, Losson R, Goff SP: Primer binding site-dependent restriction of murine leukemia virus requires HP1 binding by TRIM28. J Virol 2008, 82(9):4675-4679.

42. Rowe HM, Jakobsson J, Mesnard D, Rougemont J, Reynard S, Aktas T, Maillard PV, Layard-Liesching H, Verp S, Marquis J et al: KAP1 controls endogenous retroviruses in embryonic stem cells. Nature 2010, 463(7278):237-240.

43. Wolf D, Goff SP: TRIM28 mediates primer binding site-targeted silencing of murine leukemia virus in embryonic cells. Cell 2007, 131(1):46-57.

44. Thomas JH, Schneider S: Coevolution of retroelements and tandem zinc finger genes. Genome Res 2011, 21(11):1800-1812.

45. Imbeault M, Helleboid PY, Trono D: KRAB zinc-finger proteins contribute to the evolution of gene regulatory networks. Nature 2017.

46. Najafabadi HS, Mnaimneh S, Schmitges FW, Garton M, Lam KN, Yang A, Albu M, Weirauch MT, Radovani E, Kim PM et al: C2H2 zinc finger proteins greatly expand the human regulatory lexicon. Nat Biotechnol 2015, 33(5):555-562.

47. Schmitges FW, Radovani E, Najafabadi HS, Barazandeh M, Campitelli LF, Yin Y, Jolma A, Zhong G, Guo H, Kanagalingam T et al: Multiparameter functional diversity of human $\mathrm{C} 2 \mathrm{H} 2$ zinc finger proteins. Genome Res 2016, 26(12):1742-1752.

48. Ecco G, Cassano M, Kauzlaric A, Duc J, Coluccio A, Offner S, Imbeault M, Rowe HM, Turelli P, Trono D: Transposable Elements and Their KRABZFP Controllers Regulate Gene Expression in Adult Tissues. Dev Cell 2016, 36(6):611-623.

* $\quad$ First report of KAP1 and KRAB-ZFP repression of ERVs in differentiated mouse tissues

49. Rowe HM, Kapopoulou A, Corsinotti A, Fasching L, Macfarlan TS, Tarabay Y, Viville S, Jakobsson J, Pfaff SL, Trono D: TRIM28 repression of retrotransposon-based enhancers is necessary to preserve transcriptional dynamics in embryonic stem cells. Genome Res 2013, 23(3):452-461. 
50. Elsasser SJ, Noh KM, Diaz N, Allis CD, Banaszynski LA: Histone H3.3 is required for endogenous retroviral element silencing in embryonic stem cells. Nature 2015, 522(7555):240-244.

51. Leung D, Du T, Wagner U, Xie W, Lee AY, Goyal P, Li Y, Szulwach KE, Jin P, Lorincz MC et al: Regulation of DNA methylation turnover at LTR retrotransposons and imprinted loci by the histone methyltransferase Setdb1. Proc Natl Acad Sci U S A 2014, 111(18):6690-6695.

52. Yang BX, El Farran CA, Guo HC, Yu T, Fang HT, Wang HF, Schlesinger S, Seah YF, Goh GY, Neo SP et al: Systematic identification of factors for provirus silencing in embryonic stem cells. Cell 2015, 163(1):230-245.

53. de la Rica L, Deniz O, Cheng KC, Todd CD, Cruz C, Houseley J, Branco MR: TET-dependent regulation of retrotransposable elements in mouse embryonic stem cells. Genome Biol 2016, 17(1):234.

54. Ohnuki M, Tanabe K, Sutou K, Teramoto I, Sawamura Y, Narita M, Nakamura M, Tokunaga Y, Nakamura M, Watanabe A et al: Dynamic regulation of human endogenous retroviruses mediates factorinduced reprogramming and differentiation potential. Proc Natl Acad Sci U S A 2014, 111(34):12426-12431.

55. Corsinotti A, Kapopoulou A, Gubelmann C, Imbeault M, Santoni de Sio FR, Rowe HM, Mouscaz Y, Deplancke B, Trono D: Global and stage specific patterns of Kruppel-associated-box zinc finger protein gene expression in murine early embryonic cells. PLoS One 2014, 8(2):e56721.

56. Jacobs FM, Greenberg D, Nguyen N, Haeussler M, Ewing AD, Katzman S, Paten $B$, Salama SR, Haussler D: An evolutionary arms race between KRAB zinc-finger genes ZNF91/93 and SVA/L1 retrotransposons. Nature 2014, 516(7530):242-245.

* First functional and evolutionary characterization of human KRAB-ZNFs recognizing retrotransposons

57. Brattas PL, Jonsson ME, Fasching L, Nelander Wahlestedt J, Shahsavani M, Falk R, Falk A, Jern P, Parmar M, Jakobsson J: TRIM28 Controls a Gene Regulatory Network Based on Endogenous Retroviruses in Human Neural Progenitor Cells. Cell Rep 2017, 18(1):1-11.

58. Fasching L, Kapopoulou A, Sachdeva R, Petri R, Jonsson ME, Manne C, Turelli P, Jern P, Cammas F, Trono D et al: TRIM28 Represses Transcription of Endogenous Retroviruses in Neural Progenitor Cells. Cell Rep 2015, 10(1):20-28.

59. Turelli P, Castro-Diaz N, Marzetta F, Kapopoulou A, Raclot C, Duc J, Tieng V, Quenneville S, Trono D: Interplay of TRIM28 and DNA methylation in controlling human endogenous retroelements. Genome Res 2014, 24(8):1260-1270.

60. Hummel B, Hansen EC, Yoveva A, Aprile-Garcia F, Hussong R, Sawarkar R: The evolutionary capacitor HSP90 buffers the regulatory effects of mammalian endogenous retroviruses. Nat Struct Mol Biol 2017, 24(3):234-242.

* $\quad$ HSP90 is required to maintain ERVs repressed in differentiated macrophages 
61. Montoya-Durango DE, Ramos KA, Bojang P, Ruiz L, Ramos IN, Ramos KS: LINE-1 silencing by retinoblastoma proteins is effected through the nucleosomal and remodeling deacetylase multiprotein complex. $B M C$ cancer 2016, 16:38.

62. Chuong EB, Elde NC, Feschotte C: Regulatory evolution of innate immunity through co-option of endogenous retroviruses. Science 2016, 351(6277):1083-1087.

** The first report that ERV regulatory DNA has been co-opted in the normal functioning of the immune system

63. Zeng M, Hu Z, Shi X, Li X, Zhan X, Li XD, Wang J, Choi JH, Wang KW, Purrington T et al: MAVS, cGAS, and endogenous retroviruses in Tindependent B cell responses. Science 2014, 346(6216):1486-1492.

** This report suggests that ERV nucleic acids have been co-opted into the normal functioning of the immune system

64. Menendez L, Benigno BB, McDonald JF: L1 and HERV-W retrotransposons are hypomethylated in human ovarian carcinomas. Molecular cancer 2004, 3:12.

65. Wang-Johanning F, Li M, Esteva FJ, Hess KR, Yin B, Rycaj K, Plummer JB, Garza JG, Ambs S, Johanning GL: Human endogenous retrovirus type $K$ antibodies and mRNA as serum biomarkers of early-stage breast cancer. Int J Cancer 2014, 134(3):587-595.

66. Lamprecht B, Walter K, Kreher S, Kumar R, Hummel M, Lenze D, Kochert $\mathrm{K}$, Bouhlel MA, Richter J, Soler E et al: Derepression of an endogenous long terminal repeat activates the CSF1R proto-oncogene in human lymphoma. Nat Med 2010, 16(5):571-579, 571p following 579.

67. Szpakowski S, Sun X, Lage JM, Dyer A, Rubinstein J, Kowalski D, Sasaki C, Costa J, Lizardi PM: Loss of epigenetic silencing in tumors preferentially affects primate-specific retroelements. Gene 2009, 448(2):151-167.

68. Babaian A, Romanish MT, Gagnier L, Kuo LY, Karimi MM, Steidl C, Mager DL: Onco-exaptation of an endogenous retroviral LTR drives IRF5 expression in Hodgkin lymphoma. Oncogene 2016, 35(19):2542-2546.

* Recent demonstration that cryptic LTRs can drive oncogenes in human cancers

69. Gao D, Wu J, Wu YT, Du F, Aroh C, Yan N, Sun L, Chen ZJ: Cyclic GMP-AMP synthase is an innate immune sensor of HIV and other retroviruses. Science 2013, 341(6148):903-906.

70. Hartlova A, Erttmann SF, Raffi FA, Schmalz AM, Resch U, Anugula S, Lienenklaus S, Nilsson LM, Kroger A, Nilsson JA et al: DNA damage primes the type I interferon system via the cytosolic DNA sensor STING to promote anti-microbial innate immunity. Immunity 2015 , 42(2):332-343.

71. Rasaiyaah J, Tan CP, Fletcher AJ, Price AJ, Blondeau C, Hilditch L, Jacques DA, Selwood DL, James LC, Noursadeghi M et al: HIV-1 evades innate 
immune recognition through specific cofactor recruitment. Nature 2013, 503(7476):402-405.

72. Sun L, Wu J, Du F, Chen X, Chen ZJ: Cyclic GMP-AMP synthase is a cytosolic DNA sensor that activates the type I interferon pathway. Science 2013, 339(6121):786-791.

73. Yu P, Lubben W, Slomka H, Gebler J, Konert M, Cai C, Neubrandt L, Prazeres da Costa O, Paul S, Dehnert S et al: Nucleic acid-sensing Tolllike receptors are essential for the control of endogenous retrovirus viremia and ERV-induced tumors. Immunity 2012, 37(5):867-879.

74. Gray EE, Winship D, Snyder JM, Child SJ, Geballe AP, Stetson DB: The AIM2-like Receptors Are Dispensable for the Interferon Response to Intracellular DNA. Immunity 2016, 45(2):255-266.

75. Krishnamurthy J, Rabinovich BA, Mi T, Switzer KC, Olivares S, Maiti SN, Plummer JB, Singh H, Kumaresan PR, Huls HM et al: Genetic Engineering of T Cells to Target HERV-K, an Ancient Retrovirus on Melanoma. Clinical cancer research : an official journal of the American Association for Cancer Research 2015, 21(14):3241-3251.

76. Takahashi K, Sugi Y, Hosono A, Kaminogawa S: Epigenetic regulation of TLR4 gene expression in intestinal epithelial cells for the maintenance of intestinal homeostasis. J Immunol 2009, 183(10):6522-6529.

77. Li H, Chiappinelli KB, Guzzetta AA, Easwaran H, Yen RW, Vatapalli R, Topper MJ, Luo J, Connolly RM, Azad NS et al: Immune regulation by low doses of the DNA methyltransferase inhibitor 5-azacitidine in common human epithelial cancers. Oncotarget 2014, 5(3):587-598.

* Demonstration that interferon-responsive genes are upregulated in patients receiving 5-AZA treatment

78. Mikkelsen TS, Ku M, Jaffe DB, Issac B, Lieberman E, Giannoukos G, Alvarez P, Brockman W, Kim TK, Koche RP et al: Genome-wide maps of chromatin state in pluripotent and lineage-committed cells. Nature 2007, 448(7153):553-560.

79. Rowe HM, Friedli M, Offner S, Verp S, Mesnard D, Marquis J, Aktas T, Trono D: De novo DNA methylation of endogenous retroviruses is shaped by KRAB-ZFPs/KAP1 and ESET. Development 2013, 140(3):519-529.

80. Iqbal K, Jin SG, Pfeifer GP, Szabo PE: Reprogramming of the paternal genome upon fertilization involves genome-wide oxidation of 5methylcytosine. Proc Natl Acad Sci U S A 2011, 108(9):3642-3647.

81. Ficz G, Hore TA, Santos F, Lee HJ, Dean W, Arand J, Krueger F, Oxley D, Paul YL, Walter J et al: FGF signaling inhibition in ESCs drives rapid genome-wide demethylation to the epigenetic ground state of pluripotency. Cell Stem Cell 2013, 13(3):351-359. 
Figure 1: Epigenetic factors repress retrotransposons in differentiated tissues, preventing transcription and sensing of non-self nucleic acids. In differentiated cells, epigenetic silencing of retrotransposons is maintained by incompletely characterized mechanisms. Factors implicated in maintaining histone and DNA methylation at retrotransposons are shown. See text for details. Uncharacterized factors are depicted in blue to illustrate that this is an emerging area of research. The addition of 5-AZA-based drugs results in the generation of dsRNA from retrotransposons and potentially cDNA as well through reverse transcription, both of which lead to innate immune activation. 